\title{
miRNAs and IncRNAs in vascular injury and remodeling
}

\author{
SONG XiaoWei ${ }^{1}$, SHAN DongKai ${ }^{1}$, CHEN Jian ${ }^{2} \&$ JING Qing ${ }^{1,2^{*}}$ \\ ${ }^{1}$ Department of Cardiology, Changhai Hospital, Shanghai 200433, China; \\ ${ }^{2}$ Key Laboratory of Stem Cell Biology, Institute of Health Sciences, Shanghai Institutes for Biological Sciences, Chinese Academy of Sciences \\ \& Shanghai Jiao Tong University School of Medicine, Shanghai 200031, China
}

Received May 1, 2014; accepted June 20, 2014

\begin{abstract}
Vascular injury, remodeling, as well as angiogenesis, are the leading causes of coronary or cerebrovascular disease. The blood vessel functional imbalance trends to induce atherosclerosis, hypertension, and pulmonary arterial hypertension. As several genes have been identified to be dynamically regulated during vascular injury and remodeling, it is becoming widely accepted that several types of non-coding RNA, such as microRNAs (miRNAs) and long non-coding RNAs (lncRNAs), are involved in regulating the endothelial cell and vascular smooth muscle cell (VSMC) behaviors. Here, we review the progress of the extant studies on mechanistic, clinical and diagnostic implications of miRNAs and lncRNAs in vascular injury and remodeling, as well as angiogenesis, emphasizing the important roles of miRNAs and lncRNAs in vascular diseases. Furthermore, we introduce the interaction between miRNAs and lncRNAs, and highlight the mechanism through which lncRNAs are regulating the miRNA function. We envisage that continuous in-depth research of non-coding RNAs in vascular disease will have significant implications for the treatment of coronary or cerebrovascular diseases.
\end{abstract}

vascular injury and remodeling, coronary/cerebrovascular disease, miRNA, IncRNA, angiogenesis, endothelial cells, smooth muscle cells

Citation: $\quad$ Song XW, Shan DK, Shen J, Jing Q. miRNAs and lncRNAs in vascular injury and remodeling. Sci China Life Sci, 2014, 57: 826-835, doi: $10.1007 / \mathrm{s} 11427-014-4698-y$

Vascular network is an intricate series of vessels that act as conduits for blood flow. Their injury and remodeling contribute to atherosclerosis, restenosis after angioplasty, hypertension, and other diseases. Molecular mechanisms that underlie vascular injury and remodeling have been intensively studied during the last two decades [1-3]. As reported, a number of genes have been shown to regulate vascular remodeling and angiogenesis [4-7]. As it is increasingly acknowledged that several types of non-coding RNAs are also involved in these processes, they have become a new focus of scientific research [8].

According to the recent discoveries in the field of RNA,

*Corresponding author (email: qjing@sibs.ac.cn) nearly $60 \%$ of transcripts seem to lack protein-coding capacity, termed non-coding RNAs [9]. Bioinformatics observations suggest that non-coding RNAs tend to exist in greater numbers in more sophisticated organisms [10]. Functional studies reveal that non-coding RNAs have essential functions in regulating epigenetic processes, and emerge as important regulators of life activities [11]. Among non-coding RNAs, miRNAs and lncRNAs are particularly interesting and are thus intensively investigated. Here, we provide an overview of the extant research findings pertaining to miRNAs and lncRNAs in vascular functional maintenance, injury, remodeling, and angiogenesis. Moreover, we highlight their implications for the treatment of atherosclerosis, hypertension and other vascular-related disease. 


\section{1 miRNAs}

miRNAs are 20-25 nucleotide non-coding RNAs, present in almost all organisms, and are extensively involved in post-transcriptional regulation of gene expression [12,13]. In animal cells, miRNA is transcribed from genome as pri-miRNA, which is processed into hairpin pre-miRNA at 60-70 nucleotides length by Drosha-DGCR8 complex. After transportation from nucleus to cytoplasm by Exportin-5, pre-miRNA is cleaved by Dicer into a double-stranded molecule. After separation of duplex RNA, one is degraded and the other is integrated into RNA-induced silencing complex (RISC), which induces degradation or translational inhibition of the mRNA by interacting with its $3^{\prime}$ untranslational region through base pairing doctrine (Figure 1) [8,14-16]. Since the first miRNA was identified in Caenorhabditis elegans in 1993 [17], transcriptome-wide profiling approaches have been increasingly applied, leading to explosion of documented miRNAs $[18,19]$. Thus far, more than 1800 miRNAs in human species have been registered in miRBase 20.0. Bioinformatics analysis has shown that one miRNA might suppress hundreds of targets directly. Moreover, at least one third of protein-coding mRNAs could be regulated by miRNAs, suggesting that miRNAs could regulate many important cellular activities and basic pathophysiological processes [20-24].

\section{1 miRNAs regulate behaviors of vascular endothelial cells}

Vascular endothelial cells are a monolayer of epithelial cells that line the internal surface of blood vessels, and are thus essential for the maintenance of vascular function. Therefore, it is pivotal to understand the mechanisms of endothelial cells in vascular disease for developing therapeutic strategies. The overall loss of miRNAs in endothelial cells by depletion of Dicer [25,26], a key enzyme for miRNA maturation, induces embryonic lethality due to significant abnormality in vasculogenesis and angiogenesis, implying that miRNAs are essential for maintenance of endothelial cell function. Here, we outline the miRNAs that have thus far been adequately investigated in endothelial cells. Further, we emphasize their essential function in regulating endothelial cell behaviors, such as proliferation, migration, and association to form a primitive vascular labyrinth. These miRNAs include miR-21, miR-24, miR-34a, miR-92a, miR-126, miR-200b, miR-210, and miR-221/222 cluster (Figure 2). Many of these miRNAs inhibit angiogenesis by suppressing proliferation and migration of endothelial cells, such as miR-21 by targeting proliferators-activated receptor-alpha (PPAR- $\alpha$ ) and RhoB [27]; miR-200b by down-regulating Ets-1, VEGF, VEGFR-2 and GATA2 [28]; miR-92a by suppressing integrin subunit a5 [29]; and miR-221/222 by negatively regulating the expression of c-kit [30]. Moreover, in addition to suppressing angiogenesis by regulating GATA2, miR-24 also induces apoptosis by targeting p21-activating kinase 4 (PAK4) [31]. Similarly, miR-34a is significant in promoting senescence of endothelial cells, while it impedes angiogenesis by suppressing SIRT1 [32]. In contrast, a collection of miRNAs have been shown to promote angiogenesis. For example, we have recently reported that two loci of miR-126 are present in the

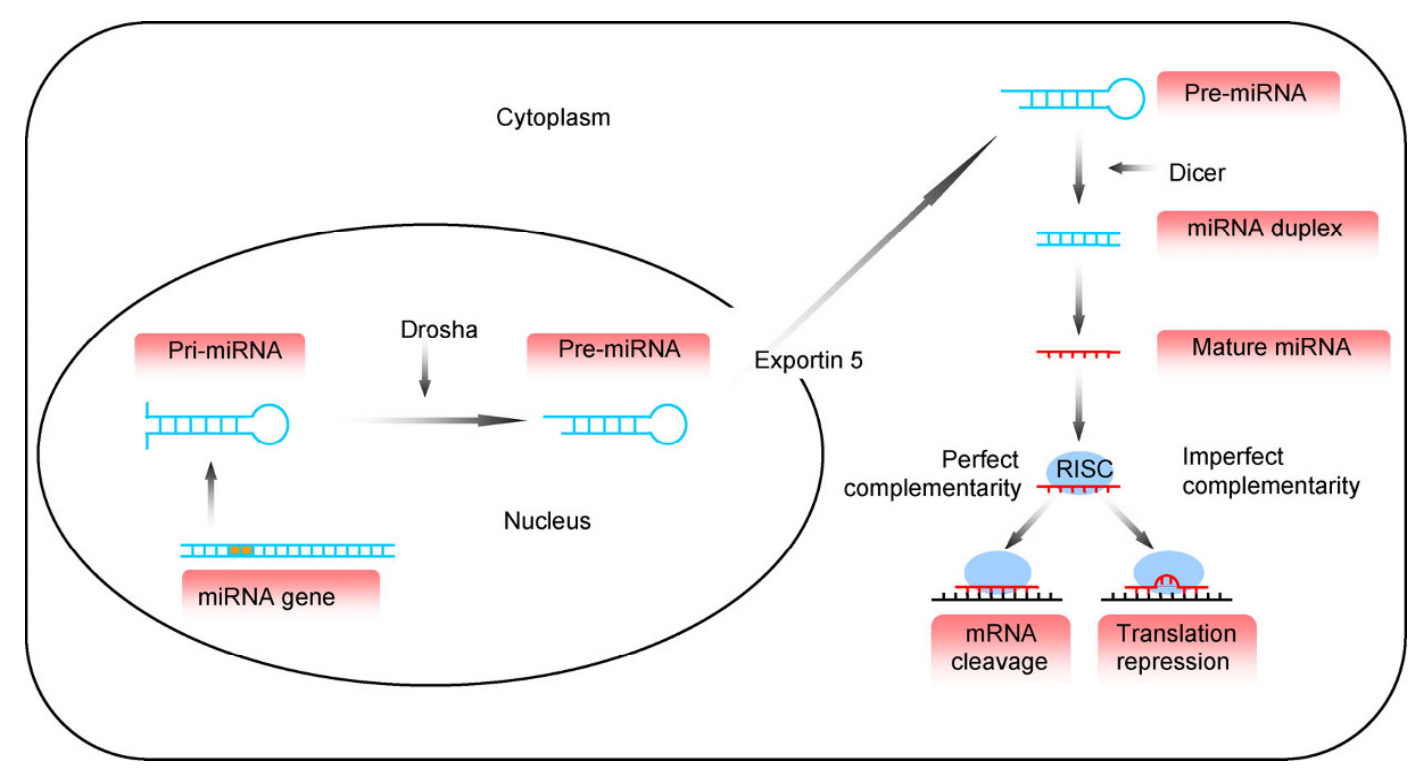

Figure 1 (color online) Standard miRNA biogenesis pathway. Primary miRNA (Pri-miRNA) is transcribed from genome by RNA polymerase II. Pri-miRNA is cleaved into hairpin Pre-miRNA in the nucleus by the endonuclease Drosha-DGCR8 complex. Pre-miRNA, at the length of 60-70 nucleotides in a stem-loop structure, is exported from the nucleus to cytoplasm by Exportin-5. In cytoplasm, pre-miRNA is further cleaved by endonuclease Dicer into a double-stranded RNA molecule. Subsequent maturation steps involve degradation of one strand RNA and integration of the other strand into RNA-induced silencing complex (RISC). miRNA in RISC induces degradation or translational suppression of target mRNA by interacting with its $3^{\prime}$ untranslational region through a base-pairing doctrine. 


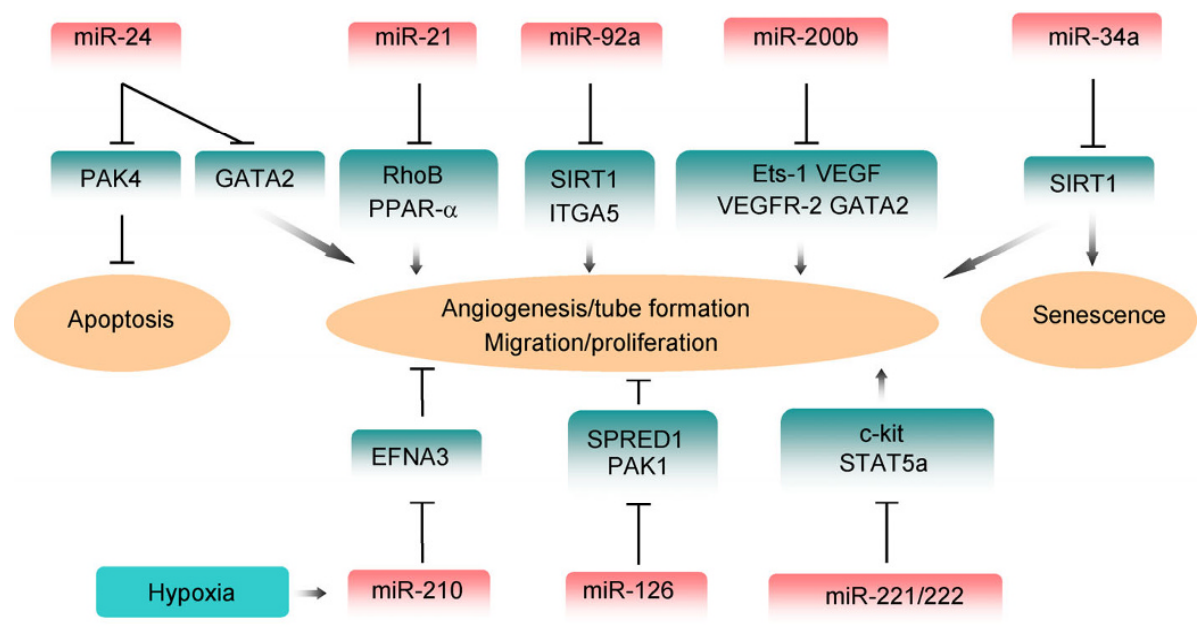

Figure 2 (color online) miRNAs in behavior regulation of endothelial cells. A collection of miRNAs is involved in regulating angiogenesis. miR-21 inhibits angiogenesis by suppressing both peroxisome proliferators-activated receptor-alpha (PPAR- $\alpha$ ) and RhoB. Similarly, miR-200b serves as a negative regulator of angiogenesis by down-regulating Ets-1, VEGF, VEGFR-2 and GATA2. MiR-92 partially blocks angiogenesis by suppressing histone deacetylase SIRT1 and integrin prime ITGA5. In contrast, miR-210 acts as a key modulator in endothelial cells survival, migration, and differentiation, as well as formation of capillary-like structures, under hypoxic conditions by inhibiting EFNA3. On the other hand, miR-221/222 causes dysfunction of endothelial cells in migration, proliferation and angiogenesis, by suppressing c-kit and STAT5, while miR-126 promotes angiogenesis through directly regulating p21-activating kinase 1 (PAK1) and SPRED1. Moreover, miR-24 is involved in apoptosis of endothelial cells by suppressing p21-activating kinase 4 (PAK4), and miR-34a significantly promotes endothelial cells senescence by regulating SIRT1, while both impede angiogenesis.

zebrafish genome, and both miR-126 can regulate vascular integrity and angiogenesis through directly regulating its target genes p21-activating kinase (PAK1) [33]. According to the results obtained in another study, miR-126 knockout mice displayed defects in angiogenesis and collateral circulation formation after myocardial ischemia. Consequently, the affected mice could not provide enough nutrients and oxygen to the ischemic myocardium, resulting in significantly increased death rate in this population [34]. Similarly, miR-210 acts as a key modulator in endothelial cell survival, migration, and differentiation, as well as formation of capillary-like structures, under hypoxic conditions [35]. In addition to the aforementioned miRNAs, other miRNAs might also participate in regulating behaviors of endothelial cells, such as miR-16, miR-424, miR-130a, Let-7, and so on [36].

\section{2 miRNAs regulate proliferation, migration and phenotypic switch of VSMC}

In addition to directly regulating gene expression in endothelial cells, a number of remarkable findings show that a variety of miRNAs are also involved in modulating proliferation and migration of VSMC by mediating vasoactive molecules, cytokines, matrix metal proteases and growth factors [37,38]. More specifically, knockout of Dicer in VSMC induces embryonic lethality, showing obviously abnormal development of vascular vessels. These findings suggest that miRNAs play important roles in proliferation, migration and phenotypic transformation of VSMC [39], such as miR-21, miR-133, miR-143/145, miR-221/222 and miR-663 (Figure 3). In response to PDGF treatment, miR$221 / 222$ is up-regulated, while miR-133, miR-143/145 and miR-663 are down-regulated. Up-regulation of miR$221 / 222$ leads to increased proliferation and migration of VSMC, as well as reduces expression of contractile markers, by directly suppressing cyclin-dependent kinase inhibitors p27Kip1 and p57Kip2 [40]. Similarly, over-expression of miR-21 increases proliferation and reduces apoptosis of VSMC [41]. On the other hand, miR-133 reduces proliferation and migration of VSMC through repressing transcription factor Sp-1 [42], while miR-143/145 inhibits proliferation and increases differentiation of VSMC, leading to repressing neointima formation following carotid artery balloon injury by directly suppressing transcription factor KLF4/5 [37]. Further knockout studies have demonstrated that loss function of the miR-143/145 significantly compromises the contractile phenotype of VSMC [43]. Another miRNA, miR-663, also increases differentiation of VSMC and inhibits PDGF-induced VSMC proliferation and migration by repressing the transcription factor JunB and myosin light chain 9 [44].

These studies demonstrate that miRNAs play important roles in vascular endothelial cells and VSMC, the two main vascular cell types, suggesting that regulation of miRNAs might be able to mediate the progress of pathological vascular damage, remodeling, as well as angiogenesis. This, in turn, might lead to improvements in the therapeutic treatment of atherosclerosis, hypertension, and restenosis after angioplasty, stroke and other vascular-related disease. 


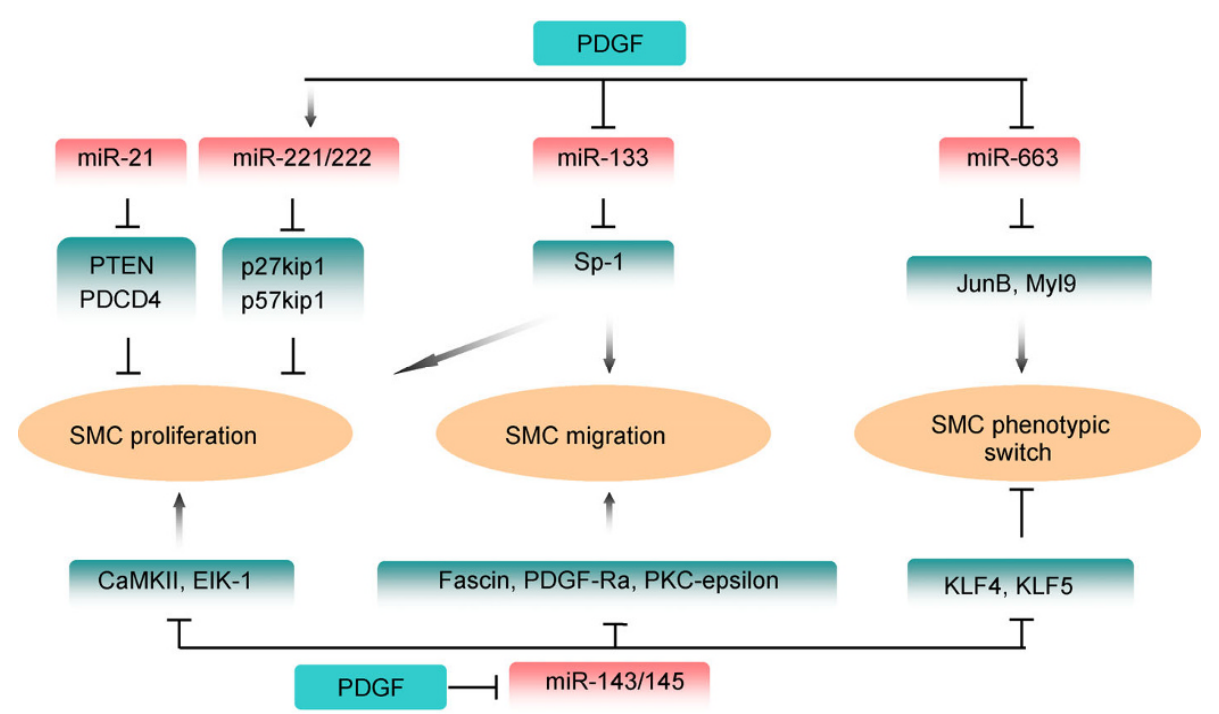

Figure 3 (color online) miRNAs regulate proliferation, migration and phenotypic switch of VSMC. In response to PDGF treatment, miR-221/222 is up-regulated, while miR-133, miR-143/145 and miR-663 are down-regulated. miR-21 increases proliferation by suppressing PTEN and PDCD4. Similarly, miR-221/222 promotes proliferation and migration by directly inhibiting cyclin-dependent kinase inhibitors p27Kip1 and p57Kip2. On the other hand, miR-143/145 inhibits proliferation by suppressing CAMK II and EIK-1, deduces migration by inhibiting Fascin, PDGF-Ra and PKC-epsilon, and switches contractile phenotype by suppressing transcription factor KLF4/5. Finally, miR-133 reduces proliferation and migration of VSMC through repressing transcription factor Sp-1. Over-expression of miR-663 increases differentiation of VSMC and inhibits PDGF-induced VSMC proliferation and migration by repressing transcription factor JunB and myosin light chain 9.

\section{3 miRNAs in vascular injury and remodeling-related disease}

Endothelium damages and vascular lumen stenosis often initiate and propagate atherosclerosis, hypertension, pulmonary arterial hypertension (PAH) and other cardiovascular diseases. Thus far, many miRNAs have been shown to participate in the pathogenesis of these processes. Here, we review the extant studies of miRNA in atherosclerosis, hypertension and PAH (Figure 4).

Atherosclerosis is one of the most common arterial syndromes stemming from vascular endothelium injury, involving multiple complex pathological processes, such as inflammation, lipid deposition, fibrosis, and plaque formation. Several miRNAs have been shown to be related with these processes. For example, we first reported a new regulatory pathway of YY1/HDACs/miR-155/HBP1 in macrophage-derived foam cell formation during early atherogenesis. We found that miR-155 was significantly increased in macrophages from atherosclerosis $\left(\mathrm{ApoE}^{-/}\right)$mice and was required to mediate oxLDL-induced lipid uptake and reactive oxygen species (ROS) production of macrophages. More importantly, inhibition of miR-155 by a systemically delivered antagomiR-155 can decrease clearly lipid-loading in macrophages and reduce atherosclerotic plaques in $A p o E^{-/}$mice, suggesting that miR-155 is a potential therapeutic target for atherosclerosis [45]. Meanwhile, Nazari-Jahantigh M1 also found that leukocyte-specific miR-155 deficiency reduced plaque size and number of lesional macrophages after partial carotid liga- tion in atherosclerotic $\left(A p o E^{-/}\right)$mice by decreasing the expression of the chemokine CCL2 [46]. In contrast, expression of miR-181b is reduced in the aortic intimae of apolipoprotein E-deficient mice fed with high-fat diets. Over-expression of miR-181b inhibits the expression of $\mathrm{NF}-\kappa \mathrm{B}$ responsive genes in endothelial cells, such as VCAM-1 and E-selectin, by directly suppressing importin- $\alpha 3$, a protein required for nuclear translocation of $\mathrm{NF}-\kappa \mathrm{B}$ [47]. These findings suggest that systemic delivery of miR-181b in vivo can suppress the progression of atherosclerosis [48]. These observations suggest that regulation of miRNAs might provide a novel therapeutic approach for atherosclerosis.

Hypertension and PAH are important outcomes of vascular remodeling, often inducing further vascular remodeling. Recent studies have shown that a collection of miRNA, such as miR-130a, miR-145, miR-155, miR-20, miR-424 and miR-503, play important roles in hypertension or PAH (Figure 4). miR-130a is up-regulated in arteries of spontaneously hypertensive rats or in angiotensin II-induced VSMC. Further inhibition of miR-130a suppresses angiotensin II-induced VSMC proliferation and vascular remodeling [36]. In contrast, miR-155 is down-regulated in arteries of spontaneously hypertensive rats, and over-expression of miR-155 inhibits hypertension by suppressing angiotensin II type 1 receptor [49]. Several miRNAs are involved in $\mathrm{PAH}$, regulating the effects of cytokines and growth factor on vascular endothelial cells or VSMC. miR-204 is down-regulated in pulmonary VSMC of humans or rodents suffering from PAH. Down-regulation of miR-204 corre- 


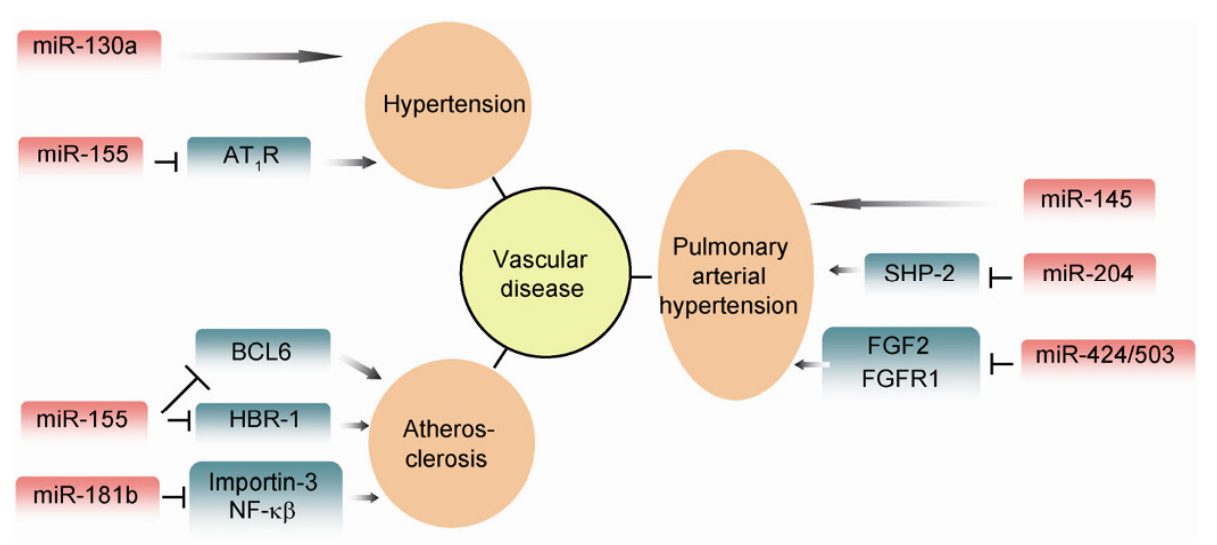

Figure 4 (color online) miRNAs in vascular disease. Over-expression of miR-181b inhibits NF- $\kappa$ B responsive genes in endothelial cells, by direct suppression of importin- $\alpha 3$, which is required for nuclear translocation of NF- $\kappa$ B. miR-155 mediates oxLDL-induced lipid uptake and reactive oxygen species (ROS) production of macrophages by suppressing HMG box-transcription protein1 (HBP1) and BCL6. Inhibition of miR-130a suppresses angiotensin II-induced VSMC proliferation and vascular remodeling. Over-expression of miR-155 inhibits hypertension by suppressing the expression of angiotensin II type 1 receptor. Down-regulation of miR-204 correlates with severity of PAH, and contributes to the proliferative and antiapoptotic phenotypes of pulmonary VSMC by derepressing SHP2. Similarly, over-expression of miR-424 or miR-503 in the pulmonary artery endothelial cells directly suppresses FGF2 and FGFR1, promotes endothelial cells into a quiescent state, inhibits the ability of pulmonary artery endothelial cells to recruit VSMC, and therefore reduces PAH. In contrast, miR-145 knockout mice display decreased right ventricular systolic pressure and hypertrophy, as well as pulmonary vascular remodeling, to a certain extent.

lates with the severity of PAH, and contributes to the proliferative and anti-apoptotic phenotypes of pulmonary VSMC by derepressing SHP2 [50]. Similarly, over-expression of miR-424 or miR-503 in pulmonary artery endothelial cells promotes endothelial cells into a quiescent state, inhibits the ability of endothelial cells to recruit VSMC, and therefore reduces PAH by directly suppressing FGF2 and FGFR1 [51]. In contrast, miR-145 has been shown to increase in lung tissues of patients with PAH, as well as PAH mice. Knock-down of miR-145 results in decreased right ventricular systolic pressure and hypertrophy, and attenuates proportion of pulmonary vascular remodeling [52]. These studies suggest that regulation of miRNA expression might lead to new therapeutic strategies for treating hypertension or PAH (Figure 4).

Recently, several studies have revealed the coordinative effects of miRNAs in phathological processes. For instances, the 3' UTR of CD44 can be combined by miR-216a, miR-330 and miR-608 to affect the expression of CDC42, thereby regulating the proliferation, apoptosis and angiogenesis phenotype of human breast cancer cell line MT-1 [53]. These studies suggest that miRNAs might also have functional relationships in vascular remodeling. Nevertheless, there is no direct experimental demonstration that miRNAs have coordinative effects in vascular remodeling thus far. However, several miRNAs were reported to be able to target the same genes in vascular injury and remodeling-related diseases, as exemplified by studies that both miR-217 and miR-34a can target Sirt1 to induce endothelial cell senescence $[54,55]$. Therefore, it is intriguingly interesting to evaluate the coordinative effects of miRNAs in vascular remodeling processes.

\subsection{Serum miRNAs might serve as biomarkers for vascular disease}

As miRNA exhibits high stability in plasma, it might be possible to utilize this characteristic in the development of molecular markers for vascular disease. We have previously found that miR-208a can be used as a serum marker for myocardial ischemia with high sensitivity and specificity [56]. Similarly, a variety of miRNAs change in plasma of patients with PAH. It has been shown that a collection of miRNAs, such as miR-451 and miR-1246, decreased, while several miRNAs, such as miR-23b, miR-130a and miR-191, increased in the plasma of patients with PAH. These studies might have important implications for clinical research aiming to establish whether miRNAs could be used as biomarkers for PAH [57]. However, as the currently available methods used for PAH detection are limited to catheterization performed under X-ray fluoroscopy, extensive work on developing simple and effective detection methods using high specificity and sensitivity plasma markers is needed. Although this study screened a variety of abnormal miRNAs in PAH plasma, it could not ascertain whether miRNAs could serve as a marker with high sensitivity and specificity for PAH.

\section{Functional relationships between miRNAs and IncRNAs}

Findings of numerous studies also indicate that the function of miRNAs is regulated post-transcriptionally by lncRNA (Figure 5). For example, BACE1as, an antisense lncRNA that arises from BACE1 locus, could increase the stability 
A
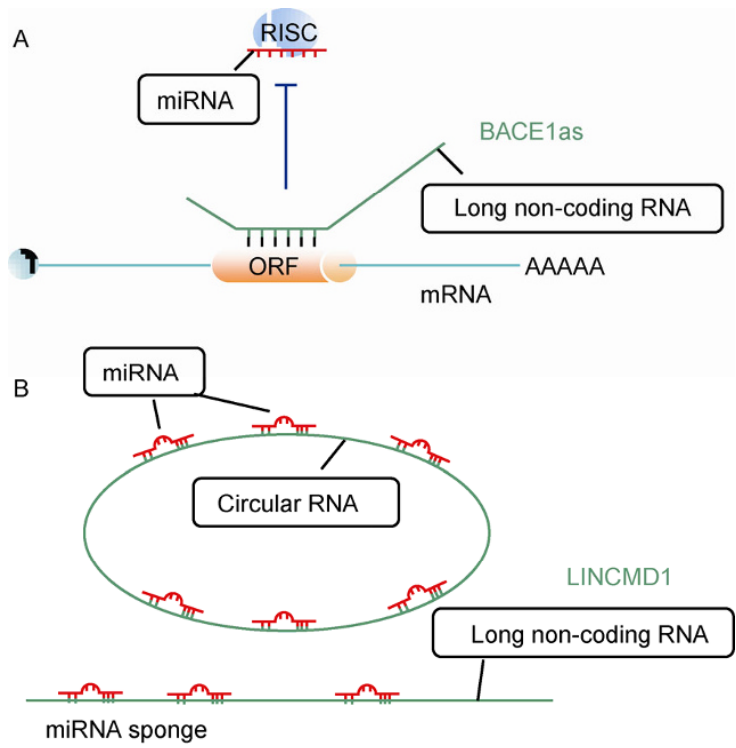

Figure 5 (color online) Functional regulating miRNA by LncRNA. A, BACE1as, an antisense LncRNA, can increase stability of BACE1 mRNA through competing for the same binding site in BACE1 with miR-485-5p. $\mathrm{B}$, Aside from competing with miRNAs on target mRNAs, a widespread crosstalk between miRNAs and lncRNAs also exists, in which lncRNAs act as decoys to attenuate the amount of miRNAs in regulation of targets mRNAs. LINCMD1, a muscle-specific lncRNA, can bind and sequester miR-133 and miR-135 to abolish their effects. Several lncRNAs have a highly stable circular structure (circRNA) and use a collection of miRNA-binding sites to fulfill their functions.

of BACE1 mRNA through competing with miR-485-5p for the same binding site in BACE1 [58,59]. Aside from competing with miRNAs on target mRNAs, there also exists a widespread crosstalk between miRNAs and lncRNAs. In this network, lncRNAs act as decoys to attenuate the amount of miRNAs in the regulation of target mRNAs (Figure 5) [60]. For instance, LINCMD1, a muscle-specific lncRNA, can bind and sequester miR-133 and miR-135 to abolish their effects on suppressing myocyte enhancer factor 2C (MEF2C) and mastermind-like 1 (MAML1) in muscle differentiation [61]. As shown in Figure 5, several lncRNAs have a highly stable circular structure (circRNA) $[62,63]$, and can find a collection of miRNA-binding sites to fulfill their functions [64].

\section{IncRNA in vascular physiological or patho- logical processes}

The function and mechanism of lncRNAs in human disease are extensively studied, demonstrating that lncRNAs regulate transcription via chromatin modulation, post-transcriptional regulation, organization of protein complexes, cellcell signalling and allosteric regulation of proteins [65-67]. However, the effects of lncRNAs, a largest part of mammalian non-coding transcriptome, are still not well understood. Only a few reports have shown that lncRNAs are involved in vascular pathophysiology. These important research advances will be reviewed below (Figure 6).

Discovery of the link between chromosome 9p21 (Chr9p21) locus and coronary artery disease by genomewide association studies marked an important landmark in vascular pathology $[68,69]$. This prompted extensive research, which indicated that this locus is associated with several vascular diseases, such as atherosclerosis, aneu-

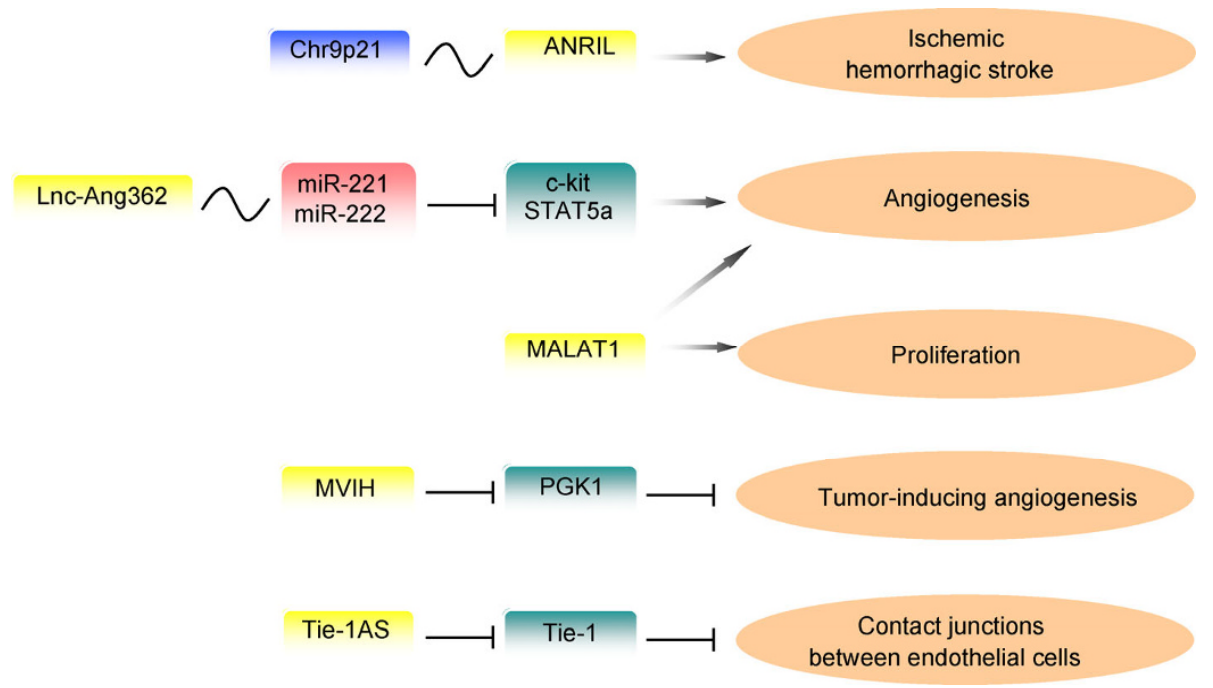

Figure 6 (color online) lncRNA in vascular physiological or pathological processes. Antisense non-coding RNA in the INK4 locus (ANRIL) was identified to be transcribed from the Chr9p21 locus, acting as an epigenetic regulator to modulate atherosclerosis, stroke and other artery disease. Tie-1AS, a natural antisense lncRNA for tyrosine kinase (tie-1), selectively binds to tie-1 mRNA to regulate its expression levels, causing specific defects of contact junctions among endothelial cells. MALAT1 promoted proliferation of endothelial cells, and thus increased angiogenesis. lncRNA MVIH is associated with microvascular invasion as well as overall survival in hepatocellular carcinoma (HCC) by promoting tumor-inducing angiogenesis through suppressing the secretion of phosphoglycerate kinase 1 (PGK1). Lnc-Ang362, the host transcript for miR-221 and miR-222, has been shown to be essential for Ang II-induced proliferation of VSMC. 
rysms, hypertension, stroke and peripheral artery disease. Recent work has shown that antisense non-coding RNA in the INK4 locus (ANRIL) is transcribed from the Chr9p21 locus and acts as an epigenetic regulator to modulate cardiovascular risks [70]. Functional studies have shown that this lncRNA may be involved in atherosclerotic process, therefore inducing ischemic and hemorrhagic stroke. This non-polyadenylated RNA was observed to resist RNase R digestion and could be amplified using outward-facing primers by PCR, suggesting that they might adopt a circular RNA structure [71].

Tie-1AS, a natural antisense lncRNA for tyrosine kinase (tie-1), selectively binds to tie-1 mRNA to regulate its expression levels in vivo and in vitro, causing specific defects in the contact junctions between endothelial cells [72]. lncRNA MVIH is associated with microvascular invasion, tumor node metastasis, decreased recurrence-free survival, as well as overall survival, in hepatocellular carcinoma by promoting tumor-inducing angiogenesis through suppressing the secretion of phosphoglycerate kinase 1 (PGK1) [73]. Therefore, by mediating the transcriptional regulation of gene expression, lncRNA could control vascular physiologic processes.

In endothelial cells, MALAT1 was significantly upregulated by hypoxia. Silencing of MALAT1 promoted sprouting and migration of endothelial cells. In vivo genetic ablation of MALAT1 suppressed proliferation of endothelial cells, and thus reduced neonatal retina vascularization. Additionally, pharmacological inhibition of MALAT1 reduced blood flow recovery and capillary density after hindlimb ischemia by impairing the expression of various cell cycle regulators. These results suggest that knockdown of MALAT1 impairs the balance of endothelial cell from a proliferative to a migratory phenotype, and further reduces vascular growth [74].

The ability of IncRNAs to associate with miRNAs and take their functions has also been investigated. For instance, aberrant regulation of angiotensin II (Ang II) results in hypertension and atherosclerosis. Using RNA-sequencing analysis, a collection of novel lncRNAs was identified in Ang II-induced VSMC. Among them, Lnc-Ang362, the host transcript for miR-221 and miR-222, was essential for proliferation of vascular smooth muscle. These results provide novel insights into lncRNAs in mediating cellular responses to Ang II [75].

\section{Problems and prospects}

Although the association between miRNAs, lncRNAs and vascular disease has been extensively studied, there are still many issues that restrict their large-scale clinical application. First, as one miRNA or lncRNAs might target dozens or even hundreds of genes, artificial intervention of these miRNAs or lncRNAs might cause unwanted changes in numerous downstream targets. Moreover, toxicity of miRNAs with chemical modification is yet to be established, and their off-target effects are still largely unknown. Thirdly, current pharmacokinetic knowledge of miRNAs or lncRNAs metabolism is still insufficient. Thus, further studies need to focus on advancing the understanding of miRNA or lncRNAs function and mechanism, in order to pave the way for clinical application of miRNAs or lncRNAs in vascular remodeling and homeostasis maintenance.

Recent studies in RNA field have primarily focused on the effects of miRNAs or IncRNAs on endothelial cells and VSMC. However, the research scope should be extended to include miRNAs or lncRNAs in other cellular components of blood vessels, such as fibroblasts and macrophage, all of which remain to be investigated. Although thousands of lncRNAs, formed as circRNAs, might be expressed across a broad range of eukaryotes, studies focusing on their functions in blood vessels are currently limited. In addition to miRNAs and lncRNAs, other non-coding RNAs, such as rasiRNAs and piRNAs, might also be involved in the development of vascular-related disease.

In this review, we highlight the mechanism of lncRNAs on vascular injury and remodeling by regulating the effects of miRNAs. However, lncRNAs also have been reported to modulate every aspects of gene expression, including chromatin remodelling, mRNA transcription and processing, and post-transcriptional pathways $[66,67,76]$. It is important, therefore, to explore whether lncRNAs could be involved in vascular disease through these mechanisms. Indeed, technical advances are already under the way to discover the functional motifs within lncRNAs and miRNAs. For instance, the application of high-throughput microfluidics-based screening technologies has the potential to analyze the functional motifs of lncRNAs and miRNAs libraries [77]. Continuing the research of the functions and mechanisms of these non-coding RNAs is urgent for their further understanding, which would clarify their mechanistic, clinical and diagnostic implications in vascular disease.

1 Higuchi K, Nakaoka Y, Shioyama W, Arita Y, Hashimoto T, Yasui T, Ikeoka K, Kuroda T, Minami T, Nishida K, Fujio Y, YamauchiTakihara K, Shirai M, Mochizuki N, Komuro I. Endothelial Gab1 deletion accelerates angiotensin II-dependent vascular inflammation and atherosclerosis in apolipoprotein E knockout mice. Circ J, 2012, 76: 2031-2040

2 Liu O, Jia L, Liu X, Wang Y, Wang X, Qin Y, Du J, Zhang H. Clopidogrel, a platelet P2Y12 receptor inhibitor, reduces vascular inflammation and angiotensin II induced-abdominal aortic aneurysm progression. PLoS ONE, 2012, 7: e51707

3 Tammela T, Zarkada G, Wallgard E, Murtomaki A, Suchting S, Wirzenius M, Waltari M, Hellstrom M, Schomber T, Peltonen R, Freitas C, Duarte A, Isoniemi H, Laakkonen P, Christofori G, Yla-Herttuala S, Shibuya M, Pytowski B, Eichmann A, Betsholtz C, Alitalo K. Blocking VEGFR-3 suppresses angiogenic sprouting and vascular network formation. Nature, 2008, 454: 656-660

4 Graupera M, Guillermet-Guibert J, Foukas LC, Phng LK, Cain RJ, 
Salpekar A, Pearce W, Meek S, Millan J, Cutillas PR, Smith AJ, Ridley AJ, Ruhrberg C, Gerhardt H, Vanhaesebroeck B. Angiogenesis selectively requires the p110alpha isoform of PI3K to control endothelial cell migration. Nature, 2008, 453: 662-666

5 Pasula S, Cai X, Dong Y, Messa M, McManus J, Chang B, Liu X, Zhu H, Mansat RS, Yoon SJ, Hahn S, Keeling J, Saunders D, Ko G, Knight J, Newton G, Luscinskas F, Sun X, Towner R, Lupu F, Xia L, Cremona O, De Camilli P, Min W, Chen H. Endothelial epsin deficiency decreases tumor growth by enhancing VEGF signaling. J Clin Invest, 2012, 122: 4424-4438

6 Stein S, Lohmann C, Schafer N, Hofmann J, Rohrer L, Besler C, Rothgiesser KM, Becher B, Hottiger MO, Boren J, McBurney MW, Landmesser U, Luscher TF, Matter CM. SIRT1 decreases Lox-1-mediated foam cell formation in atherogenesis. Eur Heart J, 2010, 31: 2301-2309

7 Evans DJ, Jackman LE, Chamberlain J, Crosdale DJ, Judge HM, Jetha K, Norman KE, Francis SE, Storey RF. Platelet P2Y(12) receptor influences the vessel wall response to arterial injury and thrombosis. Circulation, 2009, 119: 116-122

8 Ventura A, Young AG, Winslow MM, Lintault L, Meissner A, Erkeland SJ, Newman J, Bronson RT, Crowley D, Stone JR, Jaenisch $\mathrm{R}$, Sharp PA, Jacks T. Targeted deletion reveals essential and overlapping functions of the miR-17 through 92 family of miRNA clusters. Cell, 2008, 132: 875-886

9 Djebali S, Davis CA, Merkel A, Dobin A, Lassmann T. Landscape of transcription in human cells. Nature, 2012, 489: 101-108

10 Koch F, Jourquin F, Ferrier P, Andrau JC. Genome-wide RNA polymerase II: not genes only! Trends Biochem Sci, 2008, 33: 265-273

11 Carninci P, Kasukawa T, Katayama S, Gough J, Frith MC. The transcriptional landscape of the mammalian genome. Science, 2005, 309: 1559-1563

12 Grueter CE, van Rooij E, Johnson BA, DeLeon SM, Sutherland LB, Qi X, Gautron L, Elmquist JK, Bassel-Duby R, Olson EN. A cardiac microRNA governs systemic energy homeostasis by regulation of MED13. Cell, 2012, 149: 671-683

13 Zhao Y, Ransom JF, Li A, Vedantham V, von Drehle M, Muth AN, Tsuchihashi T, McManus MT, Schwartz RJ, Srivastava D. Dysregulation of cardiogenesis, cardiac conduction, and cell cycle in mice lacking miRNA-1-2. Cell, 2007, 129: 303-317

14 Lee Y, Ahn C, Han J, Choi H, Kim J, Yim J, Lee J, Provost P, Radmark O, Kim S, Kim VN. The nuclear RNase III Drosha initiates microRNA processing. Nature, 2003, 425: 415-419

15 Denli AM, Tops BB, Plasterk RH, Ketting RF, Hannon GJ. Processing of primary microRNAs by the Microprocessor complex. Nature, 2004, 432: 231-235

16 Jing Q, Huang S, Guth S, Zarubin T, Motoyama A, Chen J, Di Padova F, Lin SC, Gram H, Han J. Involvement of microRNA in AU-rich element-mediated mRNA instability. Cell, 2005, 120: 623-634

17 Lee RC, Feinbaum RL, Ambros V. The C. elegans heterochronic gene lin- 4 encodes small RNAs with antisense complementarity to lin-14. Cell, 1993, 75: 843-854

18 Hafner M, Landthaler M, Burger L, Khorshid M, Hausser J, Berninger P, Rothballer A, Ascano M, Jr., Jungkamp AC, Munschauer M, Ulrich A, Wardle GS, Dewell S, Zavolan M, Tuschl T. Transcriptome-wide identification of RNA-binding protein and microRNA target sites by PAR-CLIP. Cell, 2010, 141: 129-141

19 Lee EJ, Baek M, Gusev Y, Brackett DJ, Nuovo GJ, Schmittgen TD. Systematic evaluation of microRNA processing patterns in tissues, cell lines, and tumors. RNA, 2008, 14: 35-42

20 Song XW, Li Q, Lin L, Wang XC, Li DF, Wang GK, Ren AJ, Wang YR, Qin YW, Yuan WJ, Jing Q. MicroRNAs are dynamically regulated in hypertrophic hearts, and miR-199a is essential for the maintenance of cell size in cardiomyocytes. J Cell Physiol, 2010, 225: $437-443$
21 Chang TC, Yu D, Lee YS, Wentzel EA, Arking DE, West KM, Dang CV, Thomas-Tikhonenko A, Mendell JT. Widespread microRNA repression by Myc contributes to tumorigenesis. Nat Genet, 2008, 40: 43-50

22 Li Q, Song XW, Zou J, Wang GK, Kremneva E, Li XQ, Zhu N, Sun T, Lappalainen P, Yuan WJ, Qin YW, Jing Q. Attenuation of microRNA-1 derepresses the cytoskeleton regulatory protein twinfilin-1 to provoke cardiac hypertrophy. J Cell Sci, 2010, 123: 2444-2452

23 Xu XD, Song XW, Li Q, Wang GK, Jing Q, Qin YW. Attenuation of microRNA-22 derepressed PTEN to effectively protect rat cardiomyocytes from hypertrophy. J Cell Physiol, 2012, 227: 1391-1398

24 Fang J, Song XW, Tian J, Chen HY, Li DF, Wang JF, Ren AJ, Yuan WJ, Lin L. Overexpression of microRNA-378 attenuates ischemia-induced apoptosis by inhibiting caspase-3 expression in cardiac myocytes. Apoptosis, 2012, 17: 410-423

25 Suarez Y, Fernandez-Hernando C, Pober JS, Sessa WC. Dicer dependent microRNAs regulate gene expression and functions in human endothelial cells. Circ Res, 2007, 100: 1164-1173

26 Yang WJ, Yang DD, Na S, Sandusky GE, Zhang Q, Zhao G. Dicer is required for embryonic angiogenesis during mouse development. J Biol Chem, 2005, 280: 9330-9335

27 Zhou J, Wang KC, Wu W, Subramaniam S, Shyy JY, Chiu JJ, Li JY, Chien S. microRNA-21 targets peroxisome proliferators-activated receptor-alpha in an autoregulatory loop to modulate flow-induced endothelial inflammation. Proc Natl Acad Sci USA, 2011, 108: 10355-10360

28 Chan YC, Khanna S, Roy S, Sen CK. miR-200b targets Ets-1 and is down-regulated by hypoxia to induce angiogenic response of endothelial cells. J Biol Chem, 2011, 286: 2047-2056

29 Bonauer A, Carmona G, Iwasaki M, Mione M, Koyanagi M, Fischer A, Burchfield J, Fox H, Doebele C, Ohtani K, Chavakis E, Potente M, Tjwa M, Urbich C, Zeiher AM, Dimmeler S. microRNA-92a controls angiogenesis and functional recovery of ischemic tissues in mice. Science, 2009, 324: 1710-1713

30 Nicoli S, Knyphausen CP, Zhu LJ, Lakshmanan A, Lawson ND. miR-221 is required for endothelial tip cell behaviors during vascular development. Dev Cell, 2012, 22: 418-429

31 Fiedler J, Jazbutyte V, Kirchmaier BC, Gupta SK, Lorenzen J, Hartmann D, Galuppo P, Kneitz S, Pena JT, Sohn-Lee C, Loyer X, Soutschek J, Brand T, Tuschl T, Heineke J, Martin U, Schulte-Merker S, Ertl G, Engelhardt S, Bauersachs J, Thum T. microRNA-24 regulates vascularity after myocardial infarction. Circulation, 2011, 124: 720-730

32 Zhao $\mathrm{T}$, Li J, Chen AF. microRNA-34a induces endothelial progenitor cell senescence and impedes its angiogenesis via suppressing silent information regulator 1. Am J Physiol Endocrinol Metab, 2010, 299: E110-116

33 Zou J, Li WQ, Li Q, Li XQ, Zhang JT, Liu GQ, Chen J, Qiu XX, Tian FJ, Wang ZZ, Zhu N, Qin YW, Shen B, Liu TX, Jing Q. Two functional microRNA-126s repress a novel target gene p21-activated kinase 1 to regulate vascular integrity in zebrafish. Circ Res, 2011, 108: 201-209

34 Wang S, Aurora AB, Johnson BA, Qi X, McAnally J, Hill JA, Richardson JA, Bassel-Duby R, Olson EN. The endothelial-specific microRNA miR-126 governs vascular integrity and angiogenesis. Dev Cell, 2008, 15: 261-271

35 Lou Y, Gao F, Xie A, Guo F, Deng Z, Wang Y. microRNA-210 modified human umbilical vein endothelial cells induce capillary formation. Zhongguo Xiu Fu Chong Jian Wai Ke Za Zhi, 2012, 26: 587-591

36 Wu WH, Hu CP, Chen XP, Zhang WF, Li XW, Xiong XM, Li YJ. microRNA-130a mediates proliferation of vascular smooth muscle cells in hypertension. Am J Hypertens, 2011, 24: 1087-1093

37 Cordes KR, Sheehy NT, White MP, Berry EC, Morton SU, Muth AN, Lee TH, Miano JM, Ivey KN, Srivastava D. miR-145 and miR-143 
regulate smooth muscle cell fate and plasticity. Nature, 2009, 460: 705-710

38 Fish JE, Santoro MM, Morton SU, Yu S, Yeh RF, Wythe JD, Ivey KN, Bruneau BG, Stainier DY, Srivastava D. miR-126 regulates angiogenic signaling and vascular integrity. Dev Cell, 2008, 15: 272-284

39 Pan Y, Balazs L, Tigyi G, Yue J. Conditional deletion of Dicer in vascular smooth muscle cells leads to the developmental delay and embryonic mortality. Biochem Biophys Res Commun, 2011, 408: 369-374

40 Liu X, Cheng Y, Zhang S, Lin Y, Yang J, Zhang C. A necessary role of miR-221 and miR-222 in vascular smooth muscle cell proliferation and neointimal hyperplasia. Circ Res, 2009, 104: 476-487

41 Song J, Hu B, Qu H, Bi C, Huang X, Zhang M. Mechanical stretch modulates microRNA 21 expression, participating in proliferation and apoptosis in cultured human aortic smooth muscle cells. PLoS ONE, 2012, 7: e47657

42 Torella D, Iaconetti C, Catalucci D, Ellison GM, Leone A, Waring CD, Bochicchio A, Vicinanza C, Aquila I, Curcio A, Condorelli G, Indolfi C. microRNA-133 controls vascular smooth muscle cell phenotypic switch in vitro and vascular remodeling in vivo. Circ Res, 2011, 109: 880-893

43 Xin M, Small EM, Sutherland LB, Qi X, McAnally J, Plato CF, Richardson JA, Bassel-Duby R, Olson EN. microRNAs miR-143 and miR-145 modulate cytoskeletal dynamics and responsiveness of smooth muscle cells to injury. Genes Dev, 2009, 23: 2166-2178

44 Li P, Zhu N, Yi B, Wang N, Chen M, You X, Zhao X, Solomides CC, Qin Y, Sun J. microRNA-663 regulates human vascular smooth muscle cell phenotypic switch and vascular neointimal formation. Circ Res, 2013, 113: 1117-1127

45 Tian FJ, An LN, Wang GK, Zhu JQ, Li Q, Zhang YY, Zeng A, Zou J, Zhu RF, Han XS, Shen N, Yang HT, Zhao XX, Huang S, Qin YW, Jing Q. Elevated microRNA-155 promotes foam cell formation by targeting HBP1 in atherogenesis. Cardiovasc Res, 2014, 103: 100-110

46 Nazari-Jahantigh M, Wei Y, Noels H, Akhtar S, Zhou Z, Koenen RR, Heyll K, Gremse F, Kiessling F, Grommes J, Weber C, Schober A. MicroRNA-155 promotes atherosclerosis by repressing Bc16 in macrophages. J Clin Invest, 2012, 122: 4190-4202

47 Sun X, Icli B, Wara AK, Belkin N, He S, Kobzik L, Hunninghake GM, Vera MP, Blackwell TS, Baron RM, Feinberg MW. microRNA-181b regulates NF-kappaB-mediated vascular inflammation. J Clin Invest, 2012, 122: 1973-1990

48 Sun X, He S, Wara AK, Icli B, Shvartz E, Tesmenitsky Y, Belkin N, Li D, Blackwell TS, Sukhova GK, Croce K, Feinberg MW. Systemic delivery of microRNA-181b inhibits nuclear factor-kappaB activation, vascular inflammation, and atherosclerosis in apolipoprotein E-deficient mice. Circ Res, 2014, 114: 32-40

49 Martin MM, Lee EJ, Buckenberger JA, Schmittgen TD, Elton TS. microRNA-155 regulates human angiotensin II type 1 receptor expression in fibroblasts. J Biol Chem, 2006, 281: 18277-18284

50 Courboulin A, Paulin R, Giguere NJ, Saksouk N, Perreault T, Meloche J, Paquet ER, Biardel S, Provencher S, Cote J, Simard MJ, Bonnet S. Role for miR-204 in human pulmonary arterial hypertension. J Exp Med, 2011, 208: 535-548

51 Kim J, Kang Y, Kojima Y, Lighthouse JK, Hu X, Aldred MA, McLean DL, Park H, Comhair SA, Greif DM, Erzurum SC, Chun HJ. An endothelial apelin-FGF link mediated by miR-424 and miR-503 is disrupted in pulmonary arterial hypertension. Nat Med, 2013, 19: 74-82

52 Caruso P, Dempsie Y, Stevens HC, McDonald RA, Long L, Lu R, White K, Mair KM, McClure JD, Southwood M, Upton P, Xin M, van Rooij E, Olson EN, Morrell NW, MacLean MR, Baker AH. A role for miR-145 in pulmonary arterial hypertension: evidence from mouse models and patient samples. Circ Res, 2012, 111: 290-300

53 Jeyapalan Z, Deng Z, Shatseva T, Fang L, He C, Yang BB. Expression of CD44 3'-untranslated region regulates endogenous microRNA functions in tumorigenesis and angiogenesis. Nucleic
Acids Res, 2011, 39: 3026-3041

54 Menghini R, Casagrande V, Cardellini M, Martelli E, Terrinoni A, Amati F, Vasa-Nicotera M, Ippoliti A, Novelli G, Melino G, Lauro R, Federici M. microRNA 217 modulates endothelial cell senescence via silent information regulator 1. Circulation, 2009, 120: 1524-1532

55 Ito $\mathrm{T}$, Yagi $\mathrm{S}$, Yamakuchi $\mathrm{M}$. microRNA-34a regulation of endothelial senescence. Biochem Biophys Res Commun, 2010, 398: 735-740

56 Wang GK, Zhu JQ, Zhang JT, Li Q, Li Y, He J, Qin YW, Jing Q. Circulating microRNA: a novel potential biomarker for early diagnosis of acute myocardial infarction in humans. Eur Heart J, 2010, 31: 659-666

57 Wei C, Henderson H, Spradley C, Li L, Kim IK, Kumar S, Hong N, Arroliga AC, Gupta S. Circulating miRNAs as potential marker for pulmonary hypertension. PLoS ONE, 2013, 8: e64396

58 Faghihi MA, Modarresi F, Khalil AM, Wood DE, Sahagan BG, Morgan TE, Finch CE, St Laurent G, 3rd, Kenny PJ, Wahlestedt C. Expression of a noncoding RNA is elevated in Alzheimer's disease and drives rapid feed-forward regulation of beta-secretase. Nat Med, 2008, 14: 723-730

59 Faghihi MA, Zhang M, Huang J, Modarresi F, Van der Brug MP, Nalls MA, Cookson MR, St-Laurent G 3rd, Wahlestedt C. Evidence for natural antisense transcript-mediated inhibition of microRNA function. Genome Biol, 2010, 11: R56

60 Salmena L, Poliseno L, Tay Y, Kats L, Pandolfi PP. A ceRNA hypothesis: the Rosetta Stone of a hidden RNA language? Cell, 2011, 146: 353-358

61 Cesana M, Cacchiarelli D, Legnini I, Santini T, Sthandier O, Chinappi M, Tramontano A, Bozzoni I. A long noncoding RNA controls muscle differentiation by functioning as a competing endogenous RNA. Cell, 2011, 147: 358-369

62 Hansen TB, Jensen TI, Clausen BH, Bramsen JB, Finsen B, Damgaard CK, Kjems J. Natural RNA circles function as efficient microRNA sponges. Nature, 2013, 495: 384-388

63 Memczak S, Jens M, Elefsinioti A, Torti F, Krueger J, Rybak A, Maier L, Mackowiak SD, Gregersen LH, Munschauer M, Loewer A, Ziebold U, Landthaler M, Kocks C, le Noble F, Rajewsky N. Circular RNAs are a large class of animal RNAs with regulatory potency. Nature, 2013, 495: 333-338

64 Poliseno L, Salmena L, Zhang J, Carver B, Haveman WJ, Pandolfi PP. A coding-independent function of gene and pseudogene mRNAs regulates tumour biology. Nature, 2010, 465: 1033-1038

65 Wilusz JE, Sunwoo H, Spector DL. Long noncoding RNAs: functional surprises from the RNA world. Genes Dev, 2009, 23: 1494-1504

66 Lee JT. Epigenetic regulation by long noncoding RNAs. Science, 2012, 338: 1435-1439

67 Tsai MC, Manor O, Wan Y, Mosammaparast N, Wang JK, Lan F, Shi Y, Segal E, Chang HY. Long noncoding RNA as modular scaffold of histone modification complexes. Science, 2010, 329: 689-693

68 Helgadottir A, Thorleifsson G, Manolescu A, Gretarsdottir S, Blondal T. A common variant on chromosome 9p21 affects the risk of myocardial infarction. Science, 2007, 316: 1491-1493

69 McPherson R, Pertsemlidis A, Kavaslar N, Stewart A, Roberts R, Cox DR, Hinds DA, Pennacchio LA, Tybjaerg-Hansen A, Folsom AR, Boerwinkle E, Hobbs HH, Cohen JC. A common allele on chromosome 9 associated with coronary heart disease. Science, 2007, 316: 1488-1491

70 Holdt LM, Beutner F, Scholz M, Gielen S, Gabel G, Bergert H, Schuler G, Thiery J, Teupser D. ANRIL expression is associated with atherosclerosis risk at chromosome 9p21. Arterioscler Thromb Vasc Biol, 2010, 30: 620-627

71 Burd CE, Jeck WR, Liu Y, Sanoff HK, Wang Z, Sharpless NE. Expression of linear and novel circular forms of an INK4/ARFassociated non-coding RNA correlates with atherosclerosis risk. PLoS Genet, 2010, 6: e1001233 
72 Li K, Blum Y, Verma A, Liu Z, Pramanik K, Leigh NR, Chun CZ, Samant GV, Zhao B, Garnaas MK, Horswill MA, Stanhope SA, North PE, Miao RQ, Wilkinson GA, Affolter M, Ramchandran R. A noncoding antisense RNA in tie-1 locus regulates tie-1 function in vivo. Blood, 2010, 115: 133-139

73 Yuan SX, Yang F, Yang Y, Tao QF, Zhang J, Huang G, Wang RY, Yang S, Huo XS, Zhang L, Wang F, Sun SH, Zhou WP. Long noncoding RNA associated with microvascular invasion in hepatocellular carcinoma promotes angiogenesis and serves as a predictor for hepatocellular carcinoma patients' poor recurrence-free survival after hepatectomy. Hepatology, 2012, 56: 2231-2241

74 Michalik KM, You X, Manavski Y, Doddaballapur A, Zornig M,
Braun T, John D, Ponomareva Y, Chen W, Uchida S, Boon RA, Dimmeler S. Long noncoding RNA MALAT1 regulates endothelial cell function and vessel growth. Circ Res, 2014, 114: 1389-1397

75 Leung A, Trac C, Jin W, Lanting L, Akbany A, Saetrom P, Schones DE, Natarajan R. Novel long noncoding RNAs are regulated by angiotensin II in vascular smooth muscle cells. Circ Res, 2013, 113: 266-278

76 Mercer TR, Dinger ME, Mattick JS. Long non-coding RNAs: insights into functions. Nat Rev Genet, 2009, 10: 155-159

77 Martin L, Meier M, Lyons SM, Sit RV, Marzluff WF, Quake SR, Chang HY. Systematic reconstruction of RNA functional motifs with high-throughput microfluidics. Nat Methods, 2012, 9: 1192-1194

Open Access This article is distributed under the terms of the Creative Commons Attribution License which permits any use, distribution, and reproduction in any medium, provided the original author(s) and source are credited. 